\title{
Interaction of Müller-Lyer with filled-unfilled space illusion: An explanation of Müller-Lyer asymmetry
}

\author{
WALTER K. BEAGLEY \\ Alma College, Alma, Michigan
}

\begin{abstract}
The filled-unfilled space illusion was investigated as a possible explanation for the asymmetry (difference in strength) between tails-out and tails-in versions of the Müller-Lyer illusion. Previous work has shown that removal of the horizontal shaft makes both configurations look shorter, but affects them unequally and only partially reduces the asymmetry. In two experiments, illusion strength was varied by use of either different tail lengths or single- vs. double-ended figures. Subjects used method of adjustment with stimuli presented by computer. When the Müller-Lyer was sufficiently weak, shaft removal had equal effects on both tails-in and tails-out configurations, but less effect on plain lines. This produced a reversal of the usual asymmetry, that is, tails-in was stronger than tails-out. It is concluded that the asymmetry is caused by the filledunfilled illusion. This may require reassessment of the view that the two Müller-Lyer versions are different illusions.
\end{abstract}

As early as 1909, Lewis argued that the Müller-Lyer illusion could not be explained by any single principle. This view is now supported by a variety of studies, which have found differences between the tails-out and tails-in versions of the illusion. Of these, the best known difference is an asymmetry of strength. When tested separately, the tails-out (long) version is almost always stronger than the tails-in (short) version. In addition, the tails-out and tails-in versions respond differently to changes in such variables as the angle between shaft and tail, distance between tail tips (Sekuler \& Erlebacher, 1971), and viewing duration (Erlebacher \& Sekuler, 1974; Pollack, 1964). Finally, the two versions also respond differently to amputation of one or more of the tails (Day \& Dickinson, 1976; Greist-Bousquet \& Schiffman, 1981). Sekuler and Erlebacher noted that such differences are not easily handled by any single theory. They recommended that the two versions of the Müller-Lyer be treated as separate illusions.

A slightly different strategy is to analyze the multiple causes of the illusion in such a way that factors responsible for the differences between versions can be separated from those that contribute similarly to both versions. The present study pursues this strategy by searching for the factor or factors that cause the asymmetry of strength.

The most promising lead comes from Cooper and Runyon (1970), who reported that elimination of the horizontal shaft connecting the two sets of tails causes a

I thank David Dexter and the Alma College Computer Center for technical support, Douglas Boyne and Steve Neff for help with data collection, and Carol Slater for a critique of the writing. Requests for reprints may be sent to Walter Beagley, Department of Psychology, Alma College, Alma, MI 48801. reduction in the strength of the tails-out illusion and an increase in the strength of the tails-in version. Although they did not include a plain-line control from which to measure asymmetry, the direction of change they reported should produce a reduction or reversal of the usual asymmetry. Pressey and Moro (1971) showed that Cooper and Runyon's results could be explained by the existence of a filled-unfilled space illusion, wherein a line always looks longer than an equivalent extent of empty space. Removing the shaft makes both configurations of the illusion appear shorter, thus adding strength to the tails-in version and subtracting strength from the tails-out version. Conversely, the presence of the shaft should make both configurations look longer. By adding to the tails-out version and subtracting from the tails-in version, this might be what produces the commonly observed asymmetry.

However, a plain line with no tails attached, which is often used to control for error introduced by the measurement process, should also control for effects of the filled-unfilled illusion. The use of such a control might thus be expected to eliminate the asymmetry, but in fact it does not (e.g., Erlebacher \& Sekuler, 1974). Therefore, the filled-unfilled illusion will work as an explanation of the asymmetry only if it has a stronger effect on the Müller-Lyer figures than it has on plain lines.

Two studies employing plain-line controls (Beagley, 1982; Greist-Bousquet \& Schiffman, 1981) have not resolved this issue satisfactorily. Although shaft removal did have more effect on tails-out Müller-Lyer than on the control, the effect on the tails-in version was considerably less, approximately equal to that on the control (see Figure 1). This adds another to the growing list of differences between the two versions. Also, although shaft removal did reduce the asymmetry, it did not eliminate 


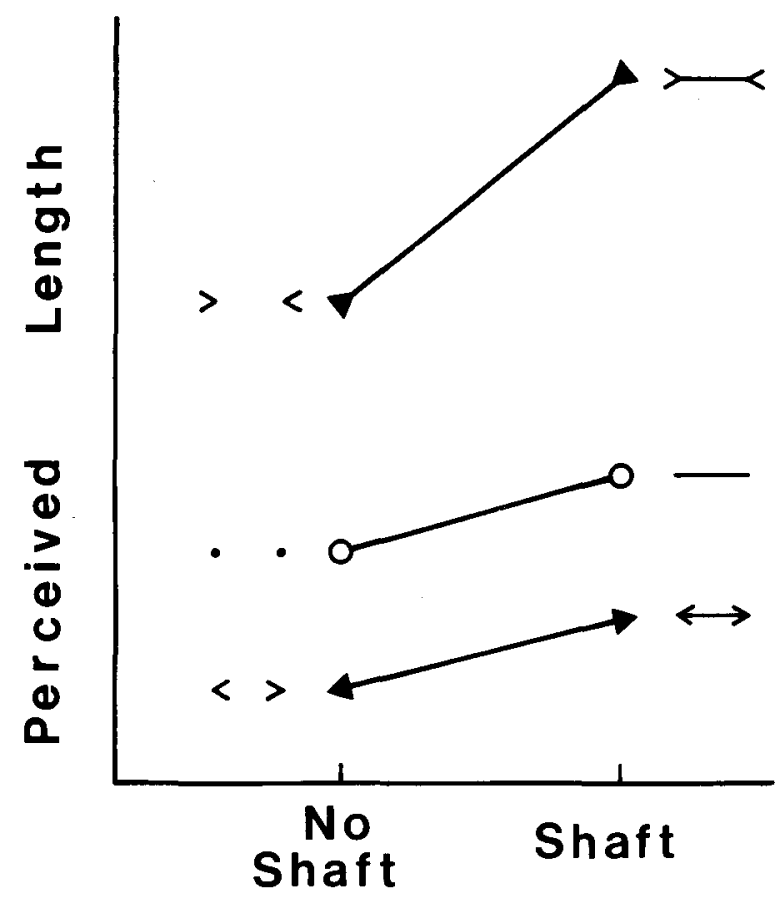

Figure 1. Effect of shaft removal on two versions of the MüllerLyer illusion. Stimulus configurations are shown adjacent to data points. Shaft removal makes all three configurations look shorter, but has greatest effect on tails-out Müller-Lyer. Asymmetry is reduced but not eliminated. (From Beagley, 1982. See also GreistBousquet \& Schiffman, 1981, Figure 3.)

or reverse it. Thus, although they appear to be related, the filled-unfilled illusion does not yet provide an adequate explanation for the Müller-Lyer asymmetry.

The two experiments reported here were designed to determine why the filled-unfilled illusion has a greater effect on one version of the Müller-Lyer than on the other. An answer to this question should clarify the relationship between the filled-unfilled illusion and the Müller-Lyer asymmetry.

\section{EXPERIMENT 1}

In order to determine why the filled-unfilled illusion has a greater effect on tails-out Müller-Lyer than on tailsin, this experiment investigated whether this difference would remain stable as the magnitude of the Müller-Lyer illusion was varied. Magnitude was changed by lengthening or shortening the tails.

\section{Method}

Subjects. The subjects were 75 volunteers, recruited from several undergraduate psychology courses.

Design. Using the method of adjustment, each subject judged six different stimuli composed from three configurations (tails-out Müller-Lyer, tails-in Müller-Lyer, and plain line) $\times$ two shaft conditions (present, absent). In the plain-line, shaft-absent stimulus, the ends of the unfilled space were marked by two small dots. Subjects were divided into five groups, each of which judged MüllerLyer figures with a different tail length.
Apparatus and Stimuli. The stimuli were presented by a DEC PDP-11/70 computer on a Tektronix 4012 (storage type) CRT graphics terminal, capable of $0.2-\mathrm{mm}$ resolution. The images appeared as bright green lines $\left(3.2 \mathrm{~cd} / \mathrm{cm}^{2}\right)$ on a dark background $\left(0.26 \mathrm{~cd} / \mathrm{cm}^{2}\right)$. The screen was $212 \times 165 \mathrm{~mm}$ and was positioned approximately $508 \mathrm{~mm}$ from the subject's eyes.

The horizontal shaft (or empty space) of all stimulus figures was $40 \mathrm{~mm}$ in length $\left(4.4^{\circ}\right.$ of visual angle). The tails were $3,5,8,12$, or $18 \mathrm{~mm}$ in length and were placed at an angle of $30^{\circ}$ from the horizontal. The adjustable line was placed above and to the right of the stimulus figure. In order to control for a tendency to underadjust, each stimulus was presented twice, once with the adjustable length at an initial value one-third longer than the stimulus, once at one-third shorter. On each trial, this value was further varied by the addition or subtraction of a randomly determined amount between $0 \%$ and $15 \%$ of the stimulus length. This ensured that the amount of adjustment required would be different for every trial.

Procedure. Each subject sat in front of the screen, listened to instructions, and made two practice adjustments before starting the experiment. On each trial, both the stimulus and the adjustable figure were drawn on the screen. If the subject judged that they looked to be different in length, he or she pushed a key that activated a set of movable cross hairs. Using dials adjacent to the keyboard, the subject then moved the cross to the point where the right end of the adjustable figure should terminate in order to equalize perceived lengths. When the key was pressed again, the cross hairs disappeared, the entire screen was erased, and the figures were redrawn with the adjustable figure at its new length. The subject was allowed to repeat the adjustment process until satisfied that the two horizontal lengths were perceptually equal. At this point, pressing a different key erased the screen, recorded the error (difference in millimeters between stimulus figure and adjustable figure), and produced the figures for the next trial. This continued until each of the six stimuli had been presented twice, in random order.

In order to prevent the subject from using specks of dust or smudges on the screen face as landmarks, the adjustable figure was moved to the right or left by a small random amount each time it was drawn or redrawn.

\section{Results}

Figure 2 shows that, for all but the shortest tail lengths, presence or absence of shaft continues to have a greater effect on the tails-out configuration. But although the tailsin Müller-Lyer shows a generally weaker filled-unfilled effect, this appears to vary inversely with tail length. The tails-in stimulus with 3-mm tails is more strongly affected by presence or absence of shaft than the one with 12- or 18-mm tails. An analysis of variance was calculated with the values obtained by subtracting the plain line control score from each illusion error score. Main effects were significant for configuration $[F(1,70)=449.5$, $p<$ $.0001]$ and tail length $[F(4,70)=10.3, p<.0001]$. The interaction between configuration and shaft condition was significant $[\mathrm{F}(1,70)=59.8, \mathrm{p}<.0001]$, as was the interaction between configuration and tail length $[\mathrm{F}(4,70)$ $=8.8, \mathrm{p}<.0001]$. Finally, the three-way interaction between configuration, shaft condition, and tail length was also marginally significant $[\mathrm{F}(4,70)=3.1, \mathrm{p}<.03]$.

\section{Discussion}

This experiment confirms that, in general, the filledunfilled illusion has a stronger effect on tails-out MüllerLyer than on tails-in. But at short tail lengths $(3 \mathrm{~mm})$, this difference disappears and both configurations are 


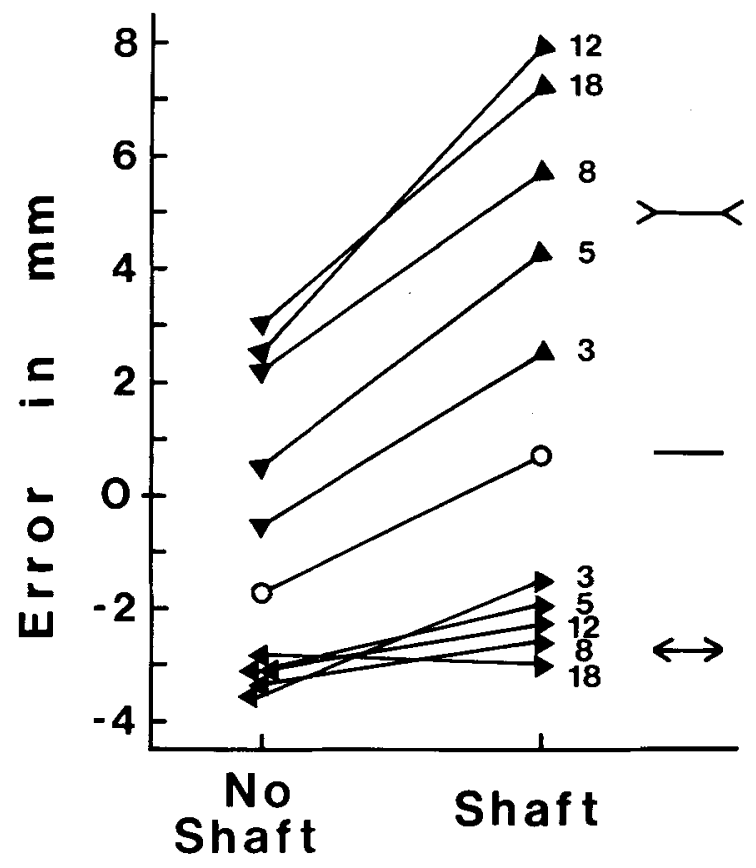

Figure 2. Effects of shaft condition and tail length on error magnitude. Tail lengths in millimeters are given at right. As tail length shortens, error decreases and the effect of shaft condition on the tails-in configuration increases.

equally affected. This three-way interaction among configuration, shaft condition, and tail length is just what one would expect if there were some type of floor effect or barrier limiting the maximum amount of perceptual shortening achievable by illusion. As long as tails are short, there is ample room for full expression of the filledunfilled effect. As tails lengthen, however, the MüllerLyer illusion becomes stronger, until the combination of Müller-Lyer and filled-unfilled illusions begins to challenge the barrier. Stimuli with the strongest negative error (tails-in, shaft-absent) would be prevented from reaching their expected values. This would explain why shaft condition usually has less effect on the tails-in configuration than on the tails-out one.

This explanation is subject to the caution that changes in tail length may have affected the relationship between the two illusions through some means other than the altering of Müller-Lyer magnitude. Experiment 2 pursues this by using a different manipulation to vary illusion magnitude.

\section{EXPERIMENT 2}

If there is some barrier or floor below which the negative tails-in illusion cannot be pushed, then any weak form of the Müller-Lyer ought to show approximately the same amount of filled-unfilled effect for both tails-in and tailsout configurations. One straightforward way of weakening the illusion is to attach tails to only one end of the shaft. This typically produces about half as much error
(Day \& Dickinson, 1976). In this experiment, singleended and double-ended Müller-Lyer illusions were compared to see whether the weaker, single-ended stimuli would produce less interaction between shaft condition and (tails-in vs. tails-out) configuration.

\section{Method}

The subjects were 50 volunteers from several undergraduate psychology courses. They were divided into two groups. One judged double-ended Müller-Lyer figures, as in the previous experiments. The other group judged single-ended figures with tails attached to the left end only. Each subject judged six stimuli composed from the same three configurations (tails-in, tails-out, and plain line) $\times$ two shaft conditions (shaft present and shaft absent). In the shaftabsent condition, dots were used to mark the ends of all stimuli not connected to tails. Shaft length was $40 \mathrm{~mm}$, and tail length was $10 \mathrm{~mm}$. The procedure was identical to that of Experiment 1.

\section{Results}

The data for double-ended figures (Figure 3, solid lines) exhibit the same pattern seen in previous experiments. Presence or absence of shaft has more effect on the tailsout version, less effect on the tails-in one. The singleended data (Figure 3, broken lines) are strikingly different. Here, shaft condition has the same effect on both versions of the Müller-Lyer and slightly less effect on the control.

An analysis of variance was calculated with the uncorrected data for the two Müller-Lyer configurations. The uncertain status of the plain-line control was examined in a separate analysis (below). Main effects were signifi-

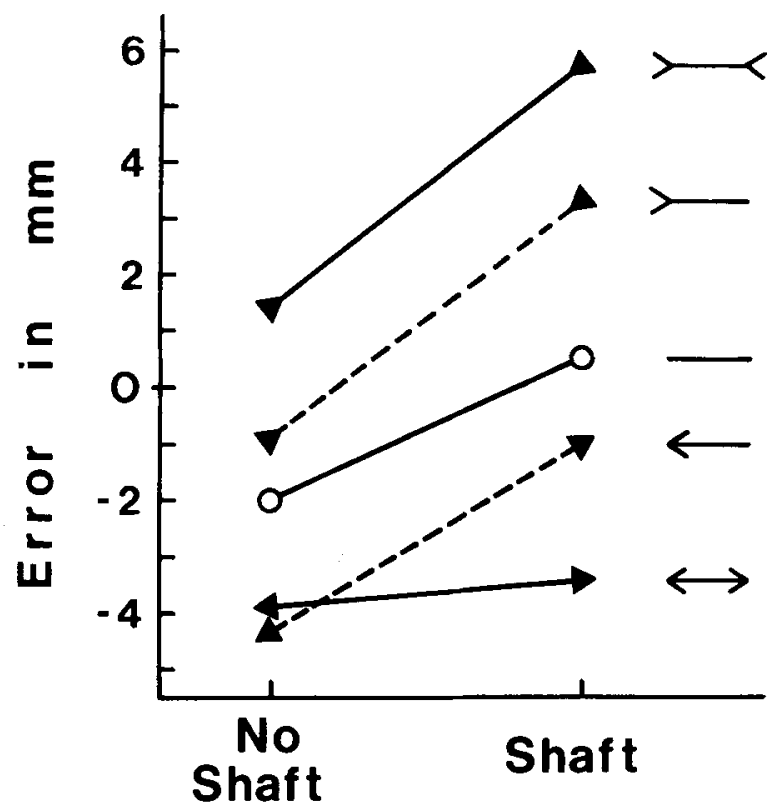

Figure 3. Effect of shaft condition on single- vs. double-ended Müller-Lyer illusion. Configurations are shown at right. Weaker, single-ended illusion figures show equal shaft condition effect for both tails-in and tails-out configurations. In the no-shaft condition, the tails-in error is further from the control than is tails-out error. This is the reverse of the asymmetry seen with shaft present. 
cant for configuration $[F(1,48)=627.6, p<.0001]$ and shaft condition $[\mathrm{F}(1,48)=109.7, \mathrm{p}<.0001]$. Because the group variable, number of ends, caused error scores for the two configurations to move in opposite directions, it did not show overall significance. Its effect is reflected in a significant interaction between configuration and number of ends $[F(1,48)=56.83, p<.0001]$. Finally, a comparison of the two groups shows that changing the illusion figures, from single ended to double ended, doubles the illusion magnitude for all stimuli except the tailsin, shaft-absent combination. This exception is reflected in the significant interaction between configuration and shaft condition $[F(1,48)=22.31, p<.0001]$, as well as the three-way interaction among configuration, shaft condition, and number of ends $[F(1,48)=9.09, p<$ $.005]$.

Two matched-pairs $T$ tests confirmed that, for singleended figures, shaft condition has a greater effect on each Müller-Lyer configuration than it has on the plain-line control [for tails out, $\mathrm{T}(24)=4.25, \mathrm{p}<.002$, one-tailed; for tails-in, $\mathrm{T}(24)=1.98, \mathrm{p}<.03$, one-tailed].

Supplementary experiment. It was noted in the introduction that the filled-unfilled illusion might serve as an explanation for the Müller-Lyer asymmetry if it had more effect on Müller-Lyer stimuli than on plain lines. All available data have shown this to be so for the tailsout configuration. In this experiment it was true also for tails-in figures of the weaker, single-ended variety. To confirm this, 22 subjects were shown four stimuli, composed from two configurations (single-ended tails-in Müller-Lyer and plain-line control) $\times$ two shaft conditions (shaft present and shaft absent). Again, presence or absence of shaft had a greater effect on the tails-in MüllerLyer than on the plain line. Mean error scores for tailsin Müller-Lyer were -4.2 and $-1.1 \mathrm{~mm}$ for shaft-absent and shaft-present, respectively. Control means were -1.6 and $0.4 \mathrm{~mm}$. An analysis of variance yielded significant main effects and a significant interaction between shaft condition and configuration $[\mathrm{F}(1,21)=5.62, \mathrm{p}<.03]$.

\section{Discussion}

This experiment supports the barrier hypothesis advanced in Experiment 1 and thus answers the original question of why the filled-unfilled illusion usually has more effect on tails-out than on tails-in stimuli. The combination of negative error produced by the strong doubleended form of the tails-in Müller-Lyer with that produced by shaft absence would exceed the limit imposed by the barrier, and so must be underrepresented in the data. The weaker, single-ended form used in this experiment avoids the barrier, resulting in approximately equal filled-unfilled effects for both tails-in and tails-out configurations.

Under these conditions, it can be seen that the filledunfilled effect is responsible for the asymmetry of strength; although the filled-unfilled effect is equal for the two Müller-Lyer configurations, it is significantly less for the plain-line control. Comparison of data for single-ended figures (Figure 3, broken lines) with the control data (open circles) shows that direction of asymmetry is reversed in the shaft-absent condition. When data are averaged across shaft conditions, the asymmetry disappears. The tails-in and tails-out illusions are of equal strength.

\section{GENERAL DISCUSSION}

The primary finding of this study is that if the MüllerLyer illusion is kept weak, either by shortening tails (Experiment 1 ) or by using a single-ended illusion figure (Experiment 2 ), the filled-unfilled illusion has equally strong effects on both tails-out and tails-in versions, but a weaker effect on plain lines. In the usual case, when shafts are present, both Müller-Lyer versions are perceptually lengthened more than the control. This leads to an exaggeration of the tails-out illusion and a diminution of the tails-in illusion, thus producing the commonly reported asymmetry. When shafts are absent, both Müller-Lyer versions are perceptually shortened more than the control, and the asymmetry is reversed. The fact that the asymmetry can be pushed either way by simply including or excluding the connecting shafts is strong support for the view that it is caused by the filled-unfilled illusion.

Another way to look at this is that the asymmetry is an artifact caused by the use of the plain-line control, which is an inadequate control for the Müller-Lyer because it does not respond equally to the filled-unfilled illusion. This artifact can be neutralized by using a weak form of the illusion and averaging data from shaft and no-shaft conditions.

A secondary finding concerns the suggested existence of a barrier or limit beyond which the strength of the tailsin Müller-Lyer cannot be increased. What might be the nature of this barrier, and why is there no equivalent barrier blocking elongation of the tails-out figure? First of all, it might not be a characteristic of the Müller-Lyer at all, but rather a failure of perfect additivity between the Müller-Lyer and filled-unfilled illusions. Coren and Ward (1979) have demonstrated that the Müller-Lyer fails to combine in a simple additive manner with most other illusions of length.

More speculatively, the barrier could be due to psychophysical or cognitive variables. For example, very powerful versions of the illusions might attract more viewer attention than other stimuli. There is evidence that perceived length increases with amount of attention (Vurpillot, 1959) or viewing duration (Erlebacher \& Sekuler, 1974). This would limit the magnitude of the tails-in Müller-Lyer, because as it became more powerful, it would attract more attention, which would increase perceived length and thus weaken the illusion. A parallel lengthening of the tails-out version would, of course, exaggerate rather than limit its magnitude.

In the present study, the effect of the barrier was significant only for the strongest negative illusion, (doubleended, shaft absent, tails-in). There is, however, no 
guarantee that this or some other "ceiling" effect may not come into play whenever a sufficiently strong illusion is produced. It might be prudent to prefer weaker forms when investigating interactions among illusion variables.

Another question is whether the filled-unfilled illusion produced here by the shaft, no-shaft manipulation is related to the Oppel-Kundt filled-unfilled illusion produced when dots divide a space into a series of smaller spaces. Both involve the filling of space and are of similar magnitude, but they may result from different processes. The phenomenon described here involves the effect of a single, uninterrupted contour. The Oppel-Kundt depends on the subdivision of a linear extent (Piaget, 1969).

Finally, it is unclear why the filled-unfilled illusion has a stronger effect on Müller-Lyer figures than on plain lines. Preliminary explorations show that lines with perpendicular tails behave like plain lines, so the difference is not caused by the mere presence or absence of appendages.

As each theory proposed to explain the Müller-Lyer has been challenged by exceptions and objections (see Over, 1968 , for review), there has grown a consensus that the illusion has multiple causes and that the two versions merit separate experimental treatment because they may have different causes (Coren, 1970; Day \& Dickinson, 1976; Greist-Bousquet \& Schiffman, 1981; Howard \& Wagner, 1973; Sekuler \& Erlebacher, 1971). The production, in this study, of a symmetrical Müller-Lyer illusion does not necessarily mean that all of the differences between the two versions have been eliminated. In addition to the differences listed in the introduction, there are factors such as length assimilation that may not affect both versions equally (Brigell, Uhlarik, \& Goldhorn, 1977; Clavadetscher \& Anderson, 1977). What this study suggests is that a multiple cause model may have to include more than two or three causal components, and that the differences between the two versions may involve only some of these. The amount of causal overlap between the two versions remains to be determined.

\section{REFERENCES}

BEAGLEy, W. (1982). [Effect of shaft removal on tails-out vs. tails-in Müller-Lyer illusion]. Unpublished data.

Brigell, M., Uhlarik, J., \& Goldhorn, P. (1977). Contextual influences on judgments of linear extent. Journal of Experimental Psychology: Human Perception and Performance, 3, 105-118.

Clavadetscher, J. E., \& ANDerson, N. H. (1977). Comparative judgment: Tests of two theories using the Baldwin figure. Journal of Experimental Psychology: Human Perception and Performance, 3, 119-135.

COOPER, M. R., \& Runyon, R. P. (1970). Error increase and decrease in minimal form of Mueller-Lyer illusion. Perceptual and Motor Skills, 31, 535-538.

Coren, S. (1970). Lateral inhibition and geometric illusions. Quarterly Journal of Experimental Psychology, 22, 274-278.

COREN, S. \& WARD, L. M. (1979). Levels of processing in visual illusions: The combination and interaction of distortion-producing mechanisms. Journal of Experimental Psychology: Human Perception and Performance, 5, 324-335.

DAY, R. H., \& DiCKINson, R. G. (1976). Apparent length of the arms of acute and obtuse angles, and the components of the Müller-Lyer illusion. Australian Journal of Psychology, 28, 137-148.

Erlebacher, A., \& Sekuler, R. (1974). Perceived length depends on exposure duration: Straight lines and Müller-Lyer stimuli. Journal of Experimental Psychology, 103, 724-728.

Greist-BousQuet, S., \& SchiffMan, H. R. (1981). The role of structural components in the Mueller-Lyer illusion. Perception \& Psychophysics, 30, 505-511.

HowarD, R. B., \& Waner, M. (1973). The role of contour and location mechanisms in the Mueller-Lyer illusion. Bulletin of the Psychonomic Society, 2, 235-236.

LEWIS, E. O. (1909). Confluxion and contrast effects in the MüllerLyer illusion. British Journal of Psychology, 3, 21-41.

OVER, R. (1968). Explanations of geometrical illusions. Psychological Bulletin, 70, 545-562.

PIAGET, J. (1969). The mechanisms of perception (pp. 62-67). London: Routledge \& Kegan Paul.

Pollack, R. H. (1964). The effects of fixation upon the apparent magnitude of bounded horizontal extent. American Journal of Psychology, 77, 177-192.

Pressey, A. W., \& Moro, T. L. (1971). An explanation of Cooper and Runyon's results on the Mueller-Lyer illusion. Perceptual and Motor Skills, 32, 564-566.

SekUler, R., \& Erlebacher, A. (1971). The two illusions of MüllerLyer: Confusion theory reexamined. American Journal of Psychology, 84, 477-486.

VuRPILlot, E. (1959). Piaget's law of relative centrations. Acta Psychologica, 16, 403-430. 